\title{
Pedo-transfer functions for saturated hydraulic conductivity of cultivated soils in the mid hills of Sikkim
}

\author{
G. T. Patle ${ }^{1, *}$ and P. C. Vanlalnunchhani ${ }^{2}$ \\ ${ }^{1}$ Department of Irrigation and Drainage Engineering, College of Agricultural Engineering and Post Harvest Technology, Ranipool 737 135, India \\ ${ }^{2}$ Department of Agricultural Engineering, North Eastern Regional Institute of Science and Technology, Nirjuli 791 109, India
}

In this study, pedotransfer functions (PTFs) are developed for saturated hydraulic conductivity $\left(K_{\mathrm{s}}\right)$ using multiple linear regression (MLR) technique for the cultivated terraced land of East Sikkim district, North East India. Soil samples were collected for 29 stations and $K_{\mathrm{s}}$ values were measured using the constant head permeameter. The various combinations of measured soil properties, including percentage of sand, silt, clay, bulk density (BD), particle density (PD), porosity, organic carbon (OC) content were used for the development of the models. The $K_{\mathrm{s}}$ value varied from 0.97 to $29.38 \mathrm{~cm} /$ day and the mean value was $8.04 \mathrm{~cm} /$ day in the study area. The correlation between predicted and measured values was found to be better for the combination, including five input variables. The results indicated a negative correlation of $K_{\mathrm{s}}$ with silt, clay and BD, whereas sand, PD, OC and porosity had a positive correlation. The recommended MLR model 5 consisting of five input variables for the prediction of $K_{\mathrm{s}}$ in the study area had $R^{2}$ values of 0.81 and 0.83 during model development and model validation, and showed goodness-of-fit with the observed $K_{\mathrm{s}}$ value. The PTFs developed in this study would be helpful for the planning and design of water resources structures in the hilly state of Sikkim.

Keywords: Cultivated land, multiple linear regression, pedotransfer functions, saturated hydraulic conductivity, soil property.

THE saturated hydraulic conductivity $\left(K_{\mathrm{s}}\right)$ is an important hydrologic property of the soil ${ }^{1}$ and is useful in the design of irrigation, drainage, groundwater recharge, and many other soil and water conservation structures ${ }^{2}$. Studies on simulation of numerous hydrological processes, flow movement and solute transport processes in agricultural fields also require $K_{\mathrm{s}}$ as a key input parameter ${ }^{3,4}$. Saturated hydraulic conductivity varies according to variation in time and space, and its direct measurement methods are tedious, costly and time-consuming ${ }^{5}$. Generally, $K_{\mathrm{s}}$ values are measured in the laboratory following a constant head or falling head permeameter. Measurements in

*For correspondence. (e-mail: gtpatle77@gmail.com) the agricultural fields are performed using piezometer, auger hole, shallow-well pumping and double-tube methods ${ }^{6,7}$. Pedotransfer functions (PTFs) are helpful for the estimation of $K_{\mathrm{s}}$ using the measured soil properties ${ }^{7}$, and are based on regression and artificial neural network (ANN) approach ${ }^{8-11}$. PTFs are statistical equations and demonstrate the relations among combinations of soil properties $^{12}$. Most of the PTFs are developed for the estimation of soil water retention and near-saturated hydraulic conductivity $\left(K_{\mathrm{s}}\right)$ using measured soil properties $^{13-16}$. The influence of soil texture, bulk density (BD), organic matter and land use has been analysed on saturated hydraulic conductivity by several researchers; it was found that PTFs of $K_{\mathrm{s}}$ were either positively or negatively correlated with one or more measured soil properties ${ }^{17,18}$. Studies also concluded that the performance of all developed PTFs could be improved by increasing the input variables in the analysis ${ }^{19-22}$. From the above, it is clear that PTFs are widely used for the prediction of $K_{\mathrm{s}}$ from the measured soil properties. In the mountainous topography of Sikkim, North East India, soil texture and other soil properties vary significantly over short distances. The entire state receives higher precipitation and is characterized by high run-off flow and soil erosion. Agricultural practices are followed mostly on terraces and hilly topography. Irrigation and water-storage structures are minimal due to topographical constraints. PTFs for saturated hydraulic conductivity would help in the design of irrigation and water conservation structures and managing the water resources and crop water in the region. But, in this hilly region, where accessibility as well as climatic conditions, are major constraints, development of a suitable model for the prediction of saturated hydraulic conductivity from soil properties is the best way to tackle the above problem.

\section{Materials and methods}

Study area

The study area is a part of the East Sikkim district. The topography of the entire district is hilly with steep terrain. 


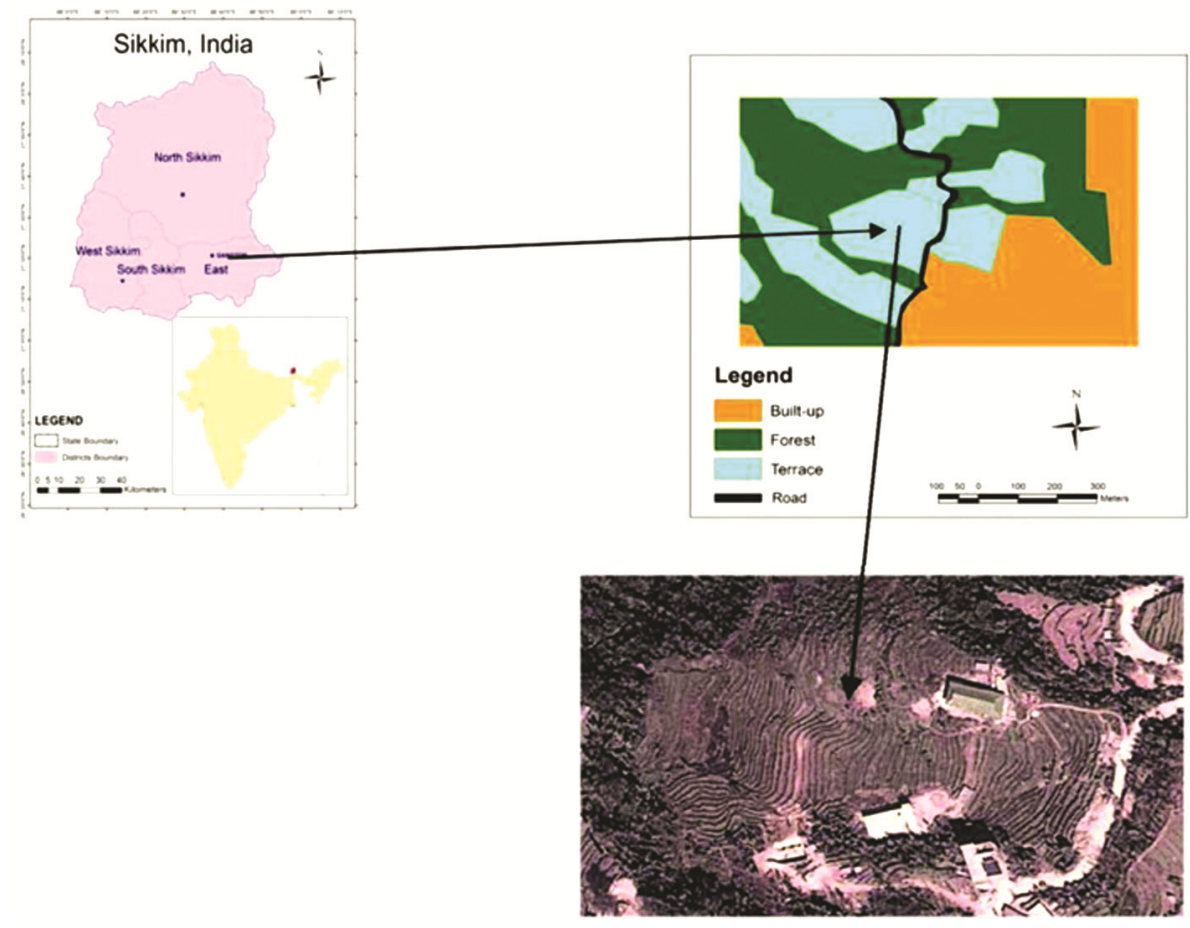

Figure 1. Study area showing the cultivated land where soil samples were retrieved.

Agriculture is the mainstay of most people and crops are cultivated on the well-settled terraces constructed on the hilly terrain. Soils vary from loamy to sandy loam ${ }^{22}$. The elevation of the study area varies from $842 \mathrm{~m}$ to $865 \mathrm{~m}$. Twenty-nine soil samples were collected from the 2000 sq. $\mathrm{m}$ area having terraced topography under cultivation. Soil samples were collected from $10 \mathrm{~m}$ grid interval from the study area (Figure 1).

\section{Methodology}

The soil properties considered for prediction of $K_{\mathrm{s}}$ were soil texture, $\mathrm{BD}$, particle density $(\mathrm{PD})$, organic carbon (OC) content and porosity. As measurement of $K_{\mathrm{s}}$ was performed in the laboratory, soil samples collected from the field were carefully handled in a wooden box for protection. The soil column was fitted with the constant head permeameter and kept over $24 \mathrm{~h}$ to achieve saturation condition. $K_{\mathrm{s}}$ values of the soil samples were measured using eq. (1) (Darcy equation). The standard procedures were used for the determination of other soil attributes.

$$
K_{s}=\frac{Q * l}{A * t * h},
$$

where $Q$ is the amount of water discharged through the soil sample $\left(\mathrm{cm}^{3}\right), l$ the length of the soil sample $(\mathrm{cm}), A$ the cross-sectional area of the core cutter $\left(\mathrm{cm}^{2}\right), t$ the duration of flow (min) and $h$ is the head of flow (cm). BD of soil samples was measured using a cylindrical core cutter of $10 \mathrm{~cm}$ diameter and $13 \mathrm{~cm}$ length, whereas PD was determined using density bottle method. The porosity of soil samples was determined from BD and PD. The texture of soil samples was analysed using the pipette method. Pusa STFR device was used to determine OC content. It gives results within a short period, and accuracy and reliability in the digital results are among its benefits.

\section{Multiple linear regression analysis}

In multiple linear regression (MLR) analysis, dependent and independent variables are linearly related. Estimated values of soil properties were used for the development of prediction models. The developed models were tested for statistical error and used for the prediction of $K_{\mathrm{s}}$. To estimate $K_{\mathrm{s}}$, a combination of one or more soil properties (input variables) was used in MLR analysis, and these were categorized into five groups. The first group had soil texture (sand, silt, clay) as an independent variable. The second group had soil texture and BD as independent variables. The third group had soil texture, BD and PD as independent variables. The fourth group had soil texture, $\mathrm{BD}, \mathrm{PD}$ and $\mathrm{OC}$ content as independent variables. The fifth group had soil texture, $\mathrm{BD}, \mathrm{PD}, \mathrm{OC}$ content and porosity as input variables. The model was developed for each group using $70 \%$ dataset and validated with $30 \%$ dataset of observations, and $K_{\mathrm{s}}$ values were estimated. The measured and predicted $K_{\mathrm{s}}$ values were compared for RMSE and coefficient of determination $\left(R^{2}\right)$. 
RESEARCH ARTICLES

Table 1. Descriptive statistics of measured soil properties in the study area

\begin{tabular}{|c|c|c|c|c|c|c|c|}
\hline Soil parameters & Minimum & Maximum & Mean & Standard error & Standard deviation & $\mathrm{CV}$ & Skewness \\
\hline Sand $(\%)$ & 62.93 & 84.00 & 74.15 & 1.013 & 5.46 & 7.36 & 0.209 \\
\hline Silt $(\%)$ & 7.36 & 20.25 & 14.32 & 0.695 & 3.75 & 26.16 & 0.050 \\
\hline Clay $(\%)$ & 5.33 & 19.07 & 11.53 & 0.678 & 3.65 & 31.66 & 0.305 \\
\hline Bulk density (BD; $\left.\mathrm{g} / \mathrm{cm}^{3}\right)$ & 1.41 & 1.68 & 1.57 & 0.016 & 0.09 & 5.42 & -0.438 \\
\hline Particle density $\left(\mathrm{PD} ; \mathrm{g} / \mathrm{cm}^{3}\right)$ & 2.00 & 2.72 & 2.53 & 0.038 & 0.20 & 8.08 & -0.909 \\
\hline Organic carbon (OC; \%) & 0.28 & 0.36 & 0.34 & 0.004 & 0.02 & 6.33 & -1.421 \\
\hline Porosity (\%) & 19.20 & 47.00 & 37.26 & 1.286 & 6.93 & 18.58 & -0.801 \\
\hline Saturated hydraulic conductivity $\left(K_{\mathrm{s}}\right)(\mathrm{cm} /$ day $)$ & 0.97 & 29.38 & 8.04 & 1.19 & 6.42 & 79.83 & 1.645 \\
\hline
\end{tabular}

The general MLR model is represented by eq. (2) as

$$
Y=A+C_{1}\left(X_{1}\right)+C_{2}\left(X_{2}\right)+\cdots+C_{\mathrm{n}}\left(X_{\mathrm{n}}\right)
$$

where $Y$ is the dependent variable, $A$ the intercept, $C$ the coefficient of the independent variable and $X$ is the independent variable.

RMSE is used to quantify the differences between values predicted by a model and the measured values. It is calculated using eq. (3).

$$
\operatorname{RMSE}=\sqrt{\frac{1}{n}\left\{\sum_{i=1}^{n}\left(x_{i}-y_{i}\right)^{2}\right\}},
$$

where $x_{i}$ is the measured value, $y_{i}$ the estimated value and $n$ is the number of values.

Standard deviation (SD) and coefficient of variation (CV) were calculated using eqs (4) and (5) as

$$
\begin{aligned}
& \mathrm{SD}=\left(\frac{1}{n}\right) \sqrt{\sum_{i=1}^{n}\left(x_{i}-x^{\prime}\right)^{2}} \\
& \mathrm{CV}=\frac{\mathrm{SD}}{x^{\prime}} * 100
\end{aligned}
$$

where $x_{i}$ is the measured value, $x^{\prime}$ the mean of measured value and $n$ is the number of measured values.

\section{Results and discussion}

\section{Measurement of saturated hydraulic conductivity}

Constant head permeameter was used for the estimation of $K_{\mathrm{s}}$ of 29 stations located in the study area. The latitude, longitude and elevation of each station were measured using GPS. It was observed that $K_{\mathrm{s}}$ value varied from 0.97 to $29.38 \mathrm{~cm} /$ day and mean value was $8.04 \mathrm{~cm} /$ day in the study area. According to the USDA textural classification, soils of the study area vary from sandy loam to loamy sand. Table 1 shows the maximum, minimum, mean value, standard error (SE), SD, CV and skewness of each soil property. Results of soil analysis revealed that sand, silt and clay varied from $62.93 \%$ to $84 \%, 7.36 \%$ to
$20.25 \%$ and $5.33 \%$ to $19.07 \%$ respectively. The per cent mean value of sand, silt and clay content was 74.15, 14.32 and 11.53 respectively. $\mathrm{BD}$ and $\mathrm{PD}$ ranged from 1.41 to $1.68 \mathrm{~g} / \mathrm{cm}^{3}$ and 2.0 to $2.72 \mathrm{~g} / \mathrm{cm}^{3}$ respectively with mean BD of $1.57 \mathrm{~g} / \mathrm{cm}^{3}$ and mean PD of $2.53 \mathrm{~g} / \mathrm{cm}^{3}$. The moisture content varied from $13.96 \%$ to $29.01 \%$, with a mean value of $24 \%$. The OC content varied from $0.28 \%$ to $0.36 \%$, with mean value of $0.34 \%$ and porosity varied from $19.20 \%$ to $47.00 \%$ with a mean value of $37.26 \%$. The coefficient of variation for sand, silt, clay, $\mathrm{BD}, \mathrm{PD}, \mathrm{OC}$ and porosity was $7.36,26.16,31.66,5.42$, $8.08,6.33$ and 18.58 respectively. The standard deviation for sand, silt, clay, BD, PD, OC and porosity were 5.46, $3.75,3.65,0.09,0.20,0.02$ and 6.93 respectively. Descriptive analysis showed that sand content had less variation whereas the per cent silt and clay showed large variation for soils in the study area, while OC showed less variation.

\section{Comparison of saturated hydraulic conductivity and soil properties}

The relationship between saturated hydraulic conductivity and individual soil properties was analysed and presented as a scatter plot. Figure $2 a-g$ shows scatter plots of per cent sand, per cent silt, per cent clay, BD, PD, OC and porosity versus saturated hydraulic conductivity $\left(K_{\mathrm{s}}\right)$ respectively. The figure depicts that $K_{\mathrm{s}}$ is either inversely or directly proportional to the measured soil attributes.

From Figure $2 a$, it can be observed that increased sand content in the soil, increases the $K_{\mathrm{s}}$ value for most of the stations, but for few stations despite the increase in sand content, the $K_{\mathrm{s}}$ value were observed to be low. This may be due to more compaction as depicted by the higher values of BD. Increase in silt content decreased the $K_{\mathrm{s}}$ value, but with less significance as $R^{2}$ was 0.0736 (Figure $2 b$ ). Figure $2 c$ shows that clay is inversely proportional to $K_{\mathrm{s}}$. It is also observed that clay would have less effect on $K_{\mathrm{s}}$ compared to silt, as depicted by the $R^{2}$ value $(0.0673)$. BD had a strong negative relationship with $K_{\mathrm{s}}$ (Figure $2 d)$. Increase in BD would decrease $K_{\mathrm{s}}$ significantly $\left(R^{2}=0.530\right)$. Similar findings were reported by the other researchers ${ }^{23}$, showing that $K_{\mathrm{s}}$ bears a negative relationship with BD. PD bears a positive correlation but shows less effect on $K_{\mathrm{s}}$ (Figure $2 e$ ). 

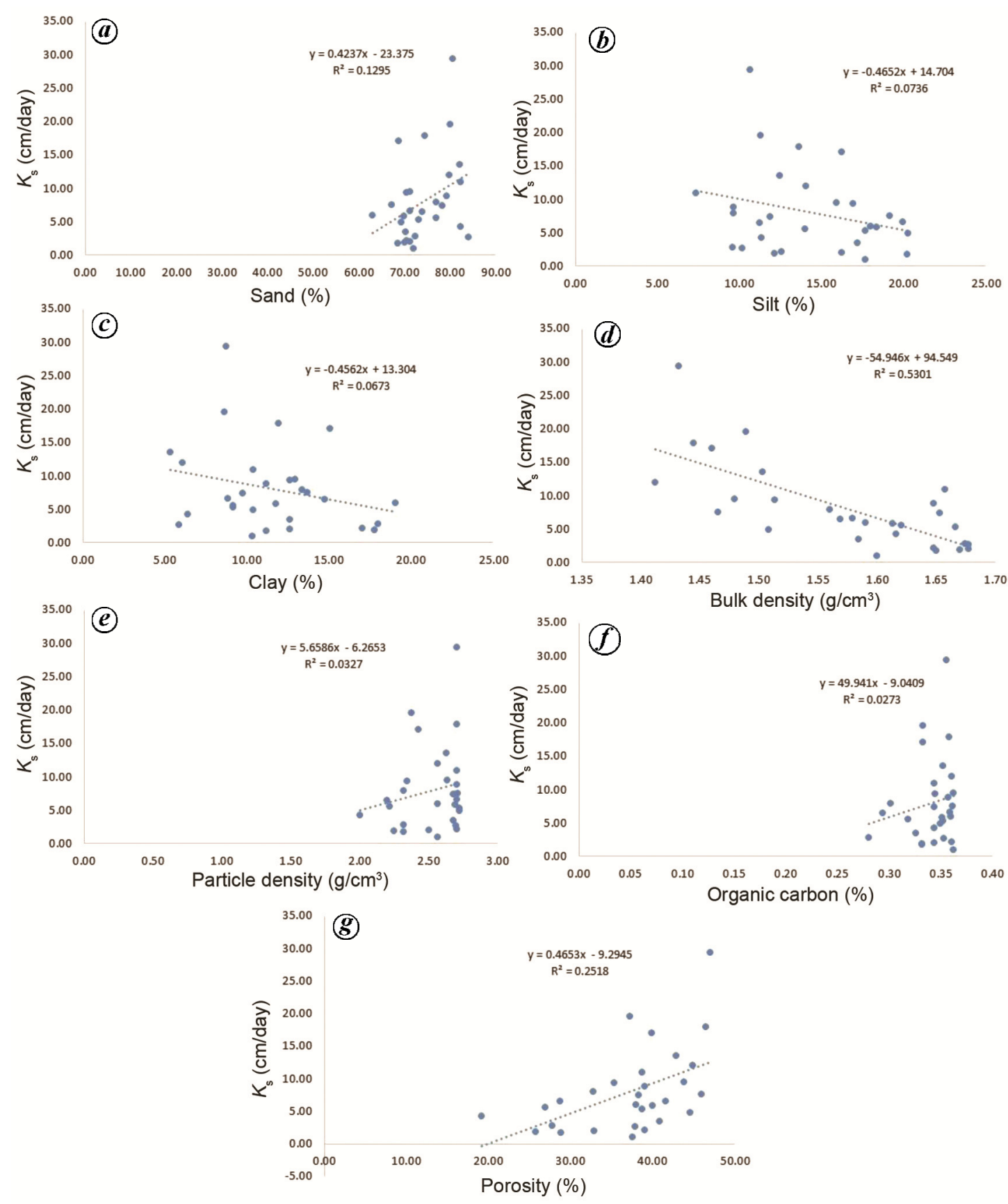

Figure 2. $\boldsymbol{a}-\boldsymbol{g}$, Scatter plots between different soil properties and $K_{\mathrm{S}}$ values in the study area.

In general, $\mathrm{OC}$ content has a strong positive correlation with $K_{\mathrm{s}}$ as reported in the many studies ${ }^{24,25}$. But from Figure $2 f$, it was observed that the increase in OC in the soil, increases $K_{\mathrm{s}}$ with less significance as $R^{2}$ was 0.0255 , which is contradictory. Some studies also reported that OC content had less influence in saturated soils. The explanation for the above is that organic matter mainly affects retention forces, the type of force that almost does not work in saturated soils where forces are basically affected by gravity ${ }^{26}$. Hence the contribution of organic matter content in estimating $K_{\mathrm{s}}$ was less. Analysis also showed the positive correlation very less between $K_{\mathrm{s}}$ and porosity in the study area (Figure $2 \mathrm{~g}$ ).

Table 2 presents the correlation between individual soil properties and $K_{\mathrm{s}}$ values. It was observed that sand, PD, OC content and porosity had a positive correlation with $K_{\mathrm{s}}$ by $0.36,0.18,0.19$ and 0.50 respectively. This indicates that if the percentage of sand, $\mathrm{PD}, \mathrm{OC}$ and porosity increases in the soil, the $K_{\mathrm{s}}$ value would also increase. But the analysis also showed a negative correlation of $K_{\mathrm{s}}$ with silt, clay and BD by $0.27,0.26$ and 0.73 respectively. This shows that the increase in silt, clay and BD would 
RESEARCH ARTICLES

Table 2. Correlation between saturated hydraulic conductivity $\left(K_{\mathrm{s}}\right)$ and soil properties

\begin{tabular}{|c|c|c|c|c|c|c|c|c|}
\hline Soil parameter & Sand $(\%)$ & Silt $(\%)$ & Clay $(\%)$ & $\mathrm{BD}\left(\mathrm{g} / \mathrm{cm}^{3}\right)$ & $\mathrm{PD}\left(\mathrm{g} / \mathrm{cm}^{3}\right)$ & OC $(\%)$ & Porosity (\%) & Measured $K_{\mathrm{s}}(\mathrm{cm} /$ day $)$ \\
\hline Sand $(\%)$ & 1 & & & & & & & \\
\hline Silt (\%) & $0.75 * *$ & 1 & & & & & & \\
\hline Clay $(\%)$ & $-0.73 * *$ & 0.09 & 1 & & & & & \\
\hline $\mathrm{BD}\left(\mathrm{g} / \mathrm{cm}^{3}\right)$ & -0.003 & -0.17 & 0.18 & 1 & & & & \\
\hline $\operatorname{PD}\left(\mathrm{g} / \mathrm{cm}^{3}\right)$ & -0.05 & 0.21 & -0.15 & -0.13 & 1 & & & \\
\hline $\mathrm{OC}(\%)$ & -0.03 & 0.36 & -0.32 & -0.26 & $0.67 * *$ & 1 & & \\
\hline Measured $K_{\mathrm{s}}(\mathrm{cm} /$ day $)$ & 0.36 & -0.27 & -0.26 & $-0.73 * *$ & 0.18 & 0.19 & $0.50 * *$ & 1 \\
\hline
\end{tabular}

**Correlation is significant at the 0.01 level.

Table 3. Comparison of developed multiple linear regression (MLR) models for prediction of $K_{\mathrm{s}}$ based on a combination of soil properties

\begin{tabular}{|c|c|c|c|}
\hline Group & Developed MLR model with combination of soil properties & $R^{2}$ & RMSE \\
\hline 1 & $K_{\mathrm{s}}=-34276.86+342.93($ sand $\%)+342.58($ silt $\%)+342.54($ clay $\%)$ & 0.15 & 3.32 \\
\hline 2 & $K_{\mathrm{s}}=4373.98-42.9($ sand $\%)-43.3($ silt $\%)-43.05($ clay\% $)-43.64(\mathrm{BD})$ & 0.63 & 2.51 \\
\hline 3 & $K_{\mathrm{s}}=8440.77-83.62($ sand $\%)-84.04($ silt $\%)-83.75($ clay\% $)-44.48(\mathrm{BD})+2.75(\mathrm{PD})$ & 0.65 & 2.32 \\
\hline 4 & $K_{\mathrm{s}}=-3581.42+36.78($ sand $\%)+36.58($ silt $\%)+36.8($ clay $\%)-44.43(\mathrm{BD})-0.59(\mathrm{PD})-16.96(\mathrm{OM} \%)$ & 0.71 & 1.96 \\
\hline 5 & $\begin{array}{l}K_{\mathrm{s}}=-53607.3+536.19(\text { sand } \%)+536.01(\text { silt } \%)+536.05(\text { clay } \%)+62.86(\mathrm{BD})-67.47(\mathrm{PD})- \\
19.55(\mathrm{OC} \%)+2.46(\text { porosity } \%)\end{array}$ & 0.80 & 1.72 \\
\hline
\end{tabular}

Table 4. Comparison of measured $K_{\mathrm{s}}$ and predicted $K_{\mathrm{s}}$ values during the model validation process

\begin{tabular}{lll}
\hline Group & $R^{2}$ & RMSE \\
\hline 1 & 0.05 & 6.211 \\
2 & 0.74 & 3.586 \\
3 & 0.74 & 3.500 \\
4 & 0.79 & 3.058 \\
5 & 0.83 & 2.863 \\
\hline
\end{tabular}

decrease $K_{\mathrm{s}}$ value of the terrace cultivated field. Among all the soil properties, BD had the highest correlation with $K_{\mathrm{s}}$ and amongst the positive properties, porosity had the highest correlation with $K_{\mathrm{s}}$; these soil properties influence $K_{\mathrm{s}}$ to a large extent in the study area.

\section{Model development and group-wise comparison}

Table 3 presents the developed models using a combination of one or more soil properties for the estimation of saturated hydraulic conductivity and model performance. Figure $3 a-e$ shows group-wise goodness-of-fit for the measured versus estimated saturated hydraulic conductivity values. Table 3 also shows the developed prediction equations for $K_{\mathrm{s}}$. The $R^{2}$ and RMSE for group 1, group 2, group 3, group 4 and group 5 were found to be 0.15 and $3.32,0.63$ and $2.51,0.65$ and $2.32,0.71$ and $1.96,0.80$ and 1.72 respectively. It is worth mentioning that predictability of the model improves with the inclusion of BD, $\mathrm{PD}$, organic matter content and porosity, and the group 5 model yielded closer predictions of saturated hydraulic conductivity.

Model validation was performed and adjudged by $R^{2}$ and RMSE for all five developed models for the study area (Table 4). The coefficient of determination for group 1 , group 2, group 3, group 4 and group 5 was found to be $0.05,0.74,0.74,0.79$ and 0.83 respectively. Figure $4 a-e$ presents the closeness of measured and predicted saturated hydraulic conductivity values as scatter plots. The predictability of MLR model for group 5 was comparatively more than groups 1 to 4 . Therefore, for the study area, group 5 model is recommended for the estimation of saturated hydraulic conductivity.

From the above results, it can be observed that an increase in the independent variables increases the reliability of prediction of the model, with increase in the number of independent variables. Equation (1) had the lowest value of $R^{2}$ and highest value of RMSE, whereas eq. (5) had highest value of $R^{2}$ and lowest value of RMSE. This implies that eq. (5) is the best amongst all equations and may be recommended for the estimation of saturated hydraulic conductivity in the hilly terrain of East Sikkim district.

Cultivated terraced fields in the East Sikkim district are located at varying altitudes and the soil hydraulic properties are likely to vary at a larger extent due to variation in soil parameters and depth of the soil. Besides, the area falls under high rainfall zone, and soil erosion and high surface run-off due to steep terrain are common features. The saturated hydraulic conductivity is largely controlled by soil structural features or macro-pores. The effects of macro-pores on hydraulic properties are difficult to quantify, especially in the hilly terrain of Sikkim due to topographical features. Spring water is the major source of water in Sikkim, not only for domestic use but also for irrigation, and saturated hydraulic conductivity plays an important role in the spring water hydrology and its modelling. Findings of the present study reveal large spatial variation in the measured saturated hydraulic conductivity 

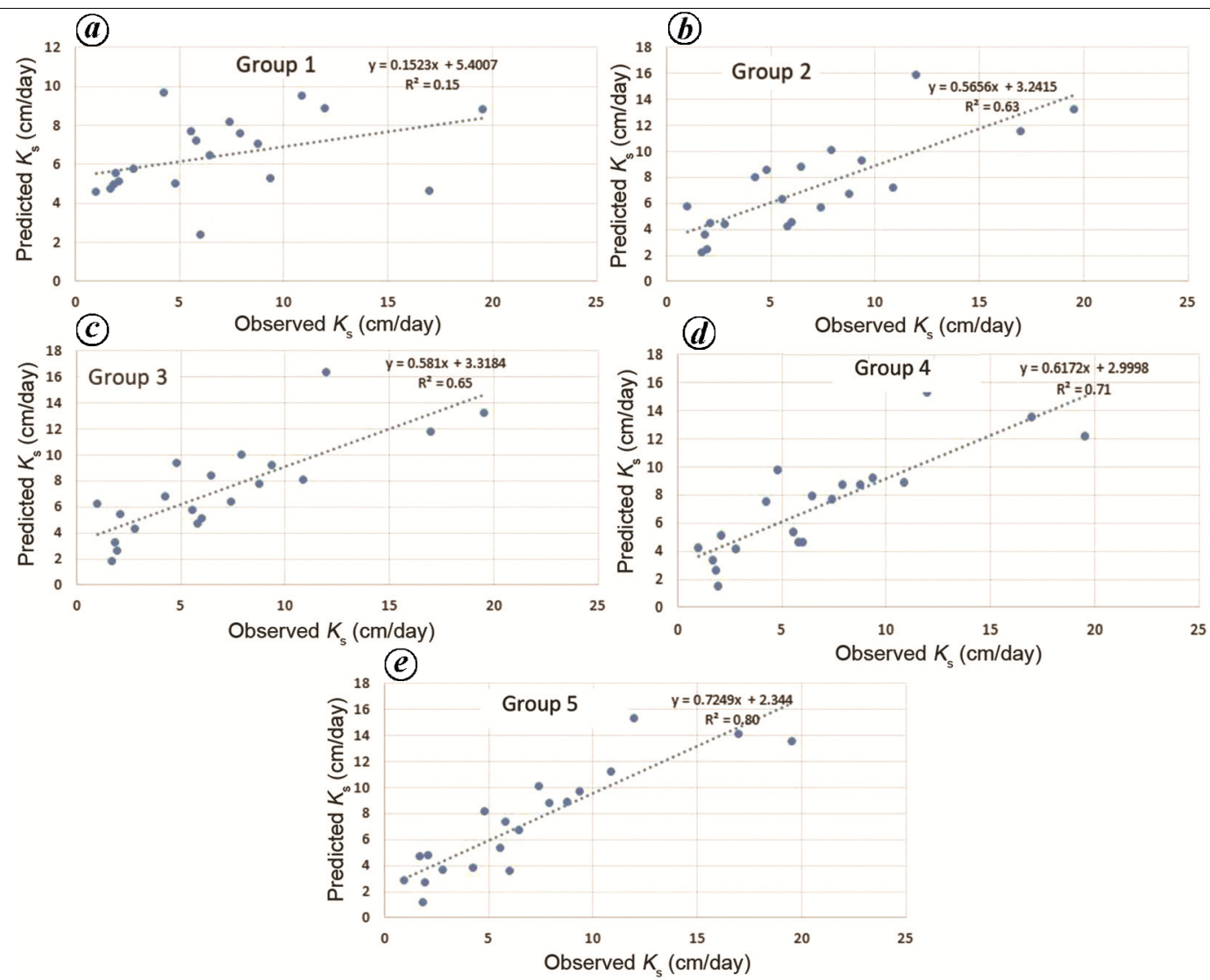

Figure 3. $\boldsymbol{a}-\boldsymbol{e}$, Measured versus estimated $K_{\mathrm{s}}$ values for the analysis of different groups (calibration models).
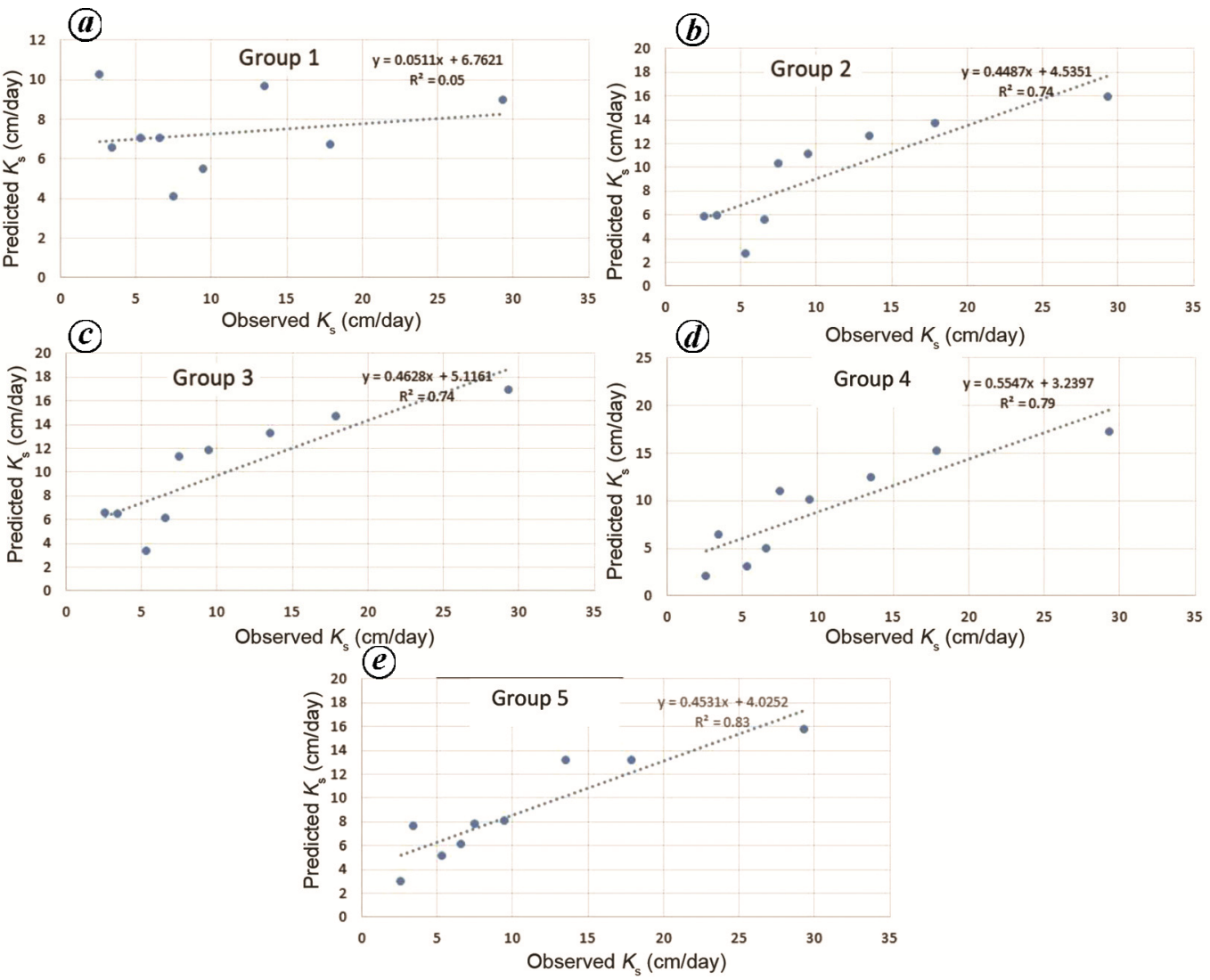

Figure 4. $\boldsymbol{a}-\boldsymbol{e}$, Measured versus estimated $K_{\mathrm{s}}$ for the analysis of different groups (for model validation). 
for the study area located at mid-altitude, considering a smaller grid size of $10 \mathrm{~m} \times 10 \mathrm{~m}$ for the measurement of $K_{\mathrm{s}}$. The developed model can be used for other areas which have similar soil properties, as the model gives significant results when $R^{2}>0.6$. Although the MLR approach has proved its effectiveness in the prediction of $K_{\text {s }}$, incorporation of field capacity and permanent wilting point with the other soil physical properties may improve the accuracy of the model.

\section{Conclusion}

Soil hydraulic properties vary to a large extent in the hilly topography. Direct methods for estimation of $K_{\mathrm{s}}$ are timeconsuming and laborious. Knowledge about the precise estimation of soil hydraulic properties using PTFs plays a vital role for the planning and design of soil and water resources structures. Considering the importance of $K_{\mathrm{s}}$, PTFs were developed for the prediction of saturated hydraulic conductivity using measured soil properties of the hilly terrain in East Sikkim district. Soil analysis showed large spatial variation in soil parameters and consequently, the effects on saturated hydraulic conductivity within a small, hilly, cultivated terrain. The MLR approach proved its effectiveness for the development of PTFs with improved predictability by increasing input variables. The developed PTFs would be useful for the estimation of saturated hydraulic conductivity in areas having similar soil characteristics.

1. Obiero, J. P. O., Gumbe, L. O., Christian, T., Omuto, C. T., Hassan, M. A. and Agullo, J. O., Development of pedotransfer functions for saturated hydraulic conductivity. Open J. Mod. Hydrol., 2013, 3, 154-164.

2. Patil, N. G., Rajput, G. S., Singh, R. B. and Singh, S. R., Development and evaluation of pedotransfer functions for saturated hydraulic conductivity of seasonally impounded clay soils. Agropedology, 2009, 19(1), 47-56.

3. Gwenzi, W., Hinz, C., Holmes, K., Philips, I. and Ian, J. M., Fieldscale spatial variability of saturated hydraulic conductivity on a recently constructed artificial ecosystem. Geoderma, 2011, 166(1), $43-56$.

4. Dharumarajan, S., Hegde, R., Lalitha, M., Kalaiselvi, B. and Singh, S. K., Pedotransfer functions for predicting soil hydraulic properties in semi-arid regions of Karnataka Plateau, India. Curr. Sci., 2019, 116(7), 1237-1246; doi:10.18520/cs/v116/i7/1237-1246.

5. Montzka, C., Herbst, M., Weihermüller, L., Verhoef, A. and Vereecken, H., A global data set of soil hydraulic properties and sub-grid variability of soil water retention and hydraulic conductivity curves. Earth Syst. Sci. Data, 2017, 9(2), 529-543.

6. Ryczek, M., Kruk, E., Malec, M. and Klatka, S., Comparison of pedotransfer functions for the determination of saturated hydraulic conductivity coefficient. Environ. Prot. Nat. Resour., 2017, 28(71), 25-30; doi:10.1515 /OSZN-2017-0005.

7. Chakraborty, D. et al., Prediction of hydraulic conductivity of soils from particle-size distribution. Curr. Sci., 2006, 90(11), $1526-1531$

8. Patil, N. G. and Singh, S. K., Pedotransfer functions for estimating soil hydraulic properties: a review. Pedosphere, 2016, 26(4), 417430 .
9. Boadu, F. K., Hydraulic conductivity of soils from grain-size distribution: new models. J. Geotech. Environ. Eng., 2000, 126(8), 739-746.

10. Cronican, A. E. and Gribb, M. M., Hydraulic conductivity prediction for sandy soils. Groundwater, 2004, 42(3), 459-464.

11. Merdun, H., Cnar, O., Ramazan Meral, R. and Apan, M., Comparison of artificial neural network and regression pedotransfer functions for prediction of soil water retention and saturated hydraulic conductivity. Soil Tillage Res., 2005, 90, 108-116.

12. Lake, H. R., Akbarzadeh, A. and Mehrjardi, R. T., Development of pedo transfer functions to predict soil physico-chemical and hydrological characteristics in southern coastal zones of the Caspian sea. J. Ecol. Nat. Environ., 2009, 1(7), 160-172.

13. Bouma, J., Using soil survey data for quantitative land evaluation. Adv. Soil Sci., 1989, 9, 177-213.

14. Jarvis, N. J. et al., Indirect estimation of near-saturated hydraulic conductivity from readily available soil information. Geoderma, $2002,108,1-17$.

15. Nemes, A., Rawls, W. J. and Pachepsky, Y. A., Influence of organic matter on the estimation of saturated hydraulic conductivity. Soil Sci. Soc. Am. J., 2005, 69, 1330-1337.

16. Moosavi, A. K. and Sepaskhah, A. R., Pedotransfer functions for prediction of near saturated hydraulic conductivity at different applied tensions in medium texture soils of a semi-arid region. Plant Knowl., 2012, 1(1), 1-9.

17. Aminifard, M. and Siosemarde, M., Relationship between the saturated hydraulic conductivity and the particle size distribution. Indian J. Fundam. Appl. Life Sci., 2014, 4(4), 73-80.

18. Aimrun, W. and Amin, M. S. M., Pedo-transfer function for saturated hydraulic conductivity of low land paddy soils. Paddy Water Environ., 2009, 7, 217-225.

19. Jarvis, N., Koestel, J., Messing, I., Moeys, J. and Lindah, A., Influence of soil, land use and climatic factors on the hydraulic conductivity of soil. Hydrol. Earth Syst. Sci., 2013, 17, 5185-5195.

20. Arshad, R. R., Sayyad, G. H., Mosaddeghi, M. and Gharabaghi, B., Predicting saturated hydraulic conductivity by artificial intelligence and regression models. ISRN Soil Sci., 2013; http://dx.doi.org/10.1155/2013/308159.

21. Nath, N. T. and Bhattacharya, K. G., Influence of soil texture and total organic matter content on soil hydraulic conductivity. Int. Res. J. Chem., 2014, 1(1), 002-009.

22. Sarki, A., Mirjat, M. S., Mahessar, A. A., Kori, S. M. and Qureshi, A. L., Determination of saturated hydraulic conductivity of different soil texture materials. J. Agric. Vet. Sci., 2014, 7(12), 56-62.

23. Patle, G. T., Sikar, T. T., Rawat, K. S. and Singh, S. K., Estimation of infiltration rate from soil properties using regression model for cultivated land. Geol. Ecol. Landsc., 2018; https://doi.org/ 10.1080/24749508.2018.1481633.

24. Mbagwu, J. S. C., Saturated hydraulic conductivity in relation to physical properties of soils in the Nsukka Plains, south eastern Nigeria. Geoderma, 1995, 68, 51-66.

25. Pikul, J. L. and Allmaras, R. R., Physical and chemical properties of a Haploxeroll after fifty years of residue management. Soil Sci. Soc. Am. J., 1986, 50, 214-219.

26. Rawls, W. J., Nemes, A. and Pachepky, Y. A., Effect of soil organic matter on soil hydraulic properties. In Development of Pedotransfer Functions in Soil Hydrology (eds Pachepsky, Y. A. and Rawls, W. J.), Elsevier, Amsterdam, 2005, pp. 95-114.

ACKNOWLEDGEMENTS. We thank the College of Agricultural Engineering and Post Harvest Technology (Central Agricultural University), Ranipool, Sikkim for providing the necessary facilities for field and laboratory experiments during this study.

Received 22 April 2019; revised accepted 14 November 2019

doi: $10.18520 / \mathrm{cs} / \mathrm{v} 118 / \mathrm{i} 5 / 771-777$ 